\title{
Um monumento ao sertão? Expectativas diversas em torno da construção do açude Cedro, em Quixadá-CE (1884-1906)
}

\section{A monument to the hinterland? Expectations about the construction of the Cedro Weir in Quixada CE (1884-1906)}

\section{Renata Felipe Monteiro*}

Resumo: Este artigo tem por objetivo entender o processo de construção do açude Cedro, entre 1884 e 1906, e as expectativas em torno dessa construção. Em 1884 aportou na província do Ceará a Comissão de Açudes e sua comitiva de engenheiros, com o propósito de construir um "grande açude" que resolvesse definitivamente o problema da seca, desenvolvesse as práticas agrícolas e melhorasse a vida da população. O sertão de Quixadá foi escolhido para abrigar esse grande monumento hidráulico. Pessoas com experiências diferentes, de várias partes do país e do exterior, foram para lá; no entanto, no decorrer da construção, houve inúmeras críticas e dificuldades para concluir essa obra pública: transporte deficiente, falta de mão de obra, entre outras. Além disso, o anseio do governo de obter rentabilidade com as águas do açude Cedro não se concretizou imediatamente. Dessa forma, com o passar do tempo arrefeceram-se as expectativas das autoridades governamentais e dos engenheiros de concretizarem as propostas iniciais do projeto de açudagem.

Palavras-chave: Açude Cedro; ciência; política; trabalho.

Abstract: This article explores the process of construction of the Cedro Weir between 1884 and 1906 and the expectations about its construction. In 1884, the Water Reservoir Commission and its entourage of engineers arrived in Ceará province, with the purpose of building a "great reservoir" that would definitively solve the drought problem, develop agricultural practices and

Doutoranda em História Social pela Universidade Federal do Ceará (UFC). Professora de História na Prefeitura Municipal de Fortaleza e do curso de Licenciatura em História, modalidade Ensino a Distância, da Universidade Estadual do Ceará (UECE). ORCID: https://orcid.org/0000-0002-6818-5326. E-mail: renataclio@hotmail.com. 
improve the people's lifes. The Quixadá hinterland was chosen to house this great hydraulic monument. People with different experiences, from many parts of the country and abroad went toward there, however, in the course of construction, there were countless criticisms and difficulties in completing this public work: deficient transportation, shortage of labor, among others. In addition, the Government's desire to obtain profitability with the Cedro weir's waters did not materialize immediately. In this way, over time the expectations of government authorities and engineers have reduced the initial proposals of the water Project.

Keywords: Cedro Weir; Science; Politics; Work.

Ademais, todas aquelas superfícies líquidas, esparsas em grande número e não resumidas a um Quixadá único - monumental e inútil - expostas à evaporação, acabaram reagindo sobre o clima, melhorando-o. ${ }^{1}$

A FRASE EM DESTAQUE, "Quixadá único - monumental e inútil”, escrita pelo engenheiro Euclides da Cunha $^{2}$ no livro Os sertões referia-se à obra do açude Cedro, ${ }^{3}$ localizado no sertão de Quixadá-CE, que teve sua construção iniciada em fins de 1884, sendo concluída, contudo, somente em 1906. ${ }^{4}$ Por que o respectivo engenheiro se referiu dessa forma a esse empreendimento hidráulico? Possivelmente Euclides da Cunha tivesse proferido tais palavras por achar que, durante a seca de $1900^{5}$ - que se revelou "ser a seca mais intensa de todo o século XIX (no que tange à ausência de chuvas)" ${ }^{\prime \prime}$-, o reservatório não estivesse cumprindo a função que the cabia: resolver os problemas referentes à estiagem no Ceará e que talvez fosse mais racional ter diversos açudes pelo estado, ao invés de um único, de grandes proporções, mas inútil.

A urgência para construir um grande açude no Ceará, ${ }^{7}$ que resolvesse definitivamente os problemas inerentes às estiagens, surgiu durante a seca que grassou na província entre

1 CUNHA, Euclides da. Os sertões. $1^{\text {a }}$ ed. São Paulo: Editora Cultrix, 1973. p. 64. Grifo meu.

2 Euclides da Cunha tornou-se nacionalmente conhecido ao narrar (como repórter do jornal O Estado de São Paulo) os acontecimentos da Guerra de Canudos, ocorrida no sertão baiano em fins do século XIX. Sua formação original, contudo, era a engenharia, concluindo os estudos na Escola Militar da Praia Grande-RJ. Atuou como engenheiro em diversos locais do Brasil, destacando-se profissionalmente na região Norte do país.

3 Cedro é a atual denominação do açude, mas desde o final do século XIX encontramos essa denominação nos documentos. Durante a execução das primeiras atividades, no entanto, o reservatório era denominado de açude de Quixadá. Ressaltamos que iremos utilizar as duas denominações, já que em algumas fontes encontramos Cedro ou açude de Quixadá.

4 A construção do açude Cedro (1884-1906) foi permeada por diversos percalços, havendo paralisações, acusações de desvios financeiros, falta de mão de obra, revoltas dos trabalhadores etc. Para entender melhor sobre a construção do açude Cedro, em Quixadá, e os diversos problemas que o envolveram, ver: MONTEIRO, Renata Felipe. Um monumento ao sertão: ciência, política e trabalho na construção do açude Cedro (18841906). 2012. Dissertação (Mestrado em História Social) - Universidade Federal do Ceará, Fortaleza, 2012; CÂNDIDO, Tyrone Apollo Pontes. Proletários das secas - experiências nas fronteiras do trabalho (18771919). $1^{a}$ ed. Curitiba: Appris, 2019.

5 Há registros documentais que pelo menos três estados nordestinos - Ceará, Rio Grande do Norte e Pernambuco - sofreram as consequências dessa grande seca em 1900. In: ALVES, Joaquim. História das secas - séculos XVII a XIX. Fortaleza: Fundação Waldemar Alcântara, 2003. p. 240.

6 CÂNDIDO, op. cit., 2019, p.194.

7 É necessário ressaltar que a construção de açudes no Ceará era recorrente no século XIX, havendo registros de diversos projetos menores de açudagem pela província, sendo normalmente iniciativas de particulares em suas propriedades. 
1877-79. Anteriormente a irregularidade das chuvas era percebida como um "fenômeno rural e 'natural'". ${ }^{8}$ Mas as mudanças impostas ao acesso a terra com a criação da Lei de Terras, em 1850, diminuíram as áreas de refúgio e abrigo dos camponeses nos períodos secos. Além disso, houve a proliferação das plantações algodoeiras, incentivada principalmente pelo aumento dos preços internacionais na década de 1860, impondo um novo sentido ao espaço físico, pois o que importava era ter vastas propriedades para plantar algodão. Assim, quando as dificuldades relacionadas à falta d'água tornaram-se alarmantes em 1877, as pessoas viram-se sem as mesmas possibilidades de outrora e com outro agravante: até mesmo os fazendeiros foram atingidos pela crise climática e não conseguiam "proteger" todos aqueles que pediam ajuda.

As primeiras levas de retirantes adentraram a cidade de Fortaleza, capital do Ceará, em abril de 1877. Possivelmente a descrença em ter ainda um período chuvoso os impulsionou a migrar. O percurso, porém, era repleto de obstáculos e desafios, que nem todos conseguiam transpor. Às vezes, as estradas se transformavam em túmulos para inúmeros homens, como salienta o historiador Frederico de Castro Neves:

[...] a marcha dos retirantes em direção às cidades do litoral era marcada pelos mais impressionantes obstáculos. O abandono de suas casas e plantações só acontecia quando as últimas esperanças de chuvas já se haviam desvanecido e os últimos grãos, que ficariam para as sementes, sido consumidos. Isso significa que, logo no início da jornada, já era precário o estado de saúde e de nutrição destas famílias. Já saíam famintos de suas terras. ${ }^{9}$

A presença dessas pessoas nas cidades do Ceará, sobretudo, em Fortaleza - movimentando-se pelo espaço citadino com seus corpos fétidos e macérrimos, pedindo comida, saqueando armazéns, prostituindo-se, roubando, propagando suas doenças, dentre outros achaques atemorizava a elite urbana cearense, que exigia urgentes medidas do governo provincial para solucionar esses problemas. Diante dos fatos alarmantes averiguados em território cearense e das notícias divulgadas pelos jornais locais e de outras províncias, vários grupos da sociedade brasileira debateram sobre a melhor maneira para resolver o problema da seca.

Havia aqueles que defendiam a construção de inúmeros açudes, em diversas regiões do Ceará, e o reflorestamento das áreas desmatadas, chamados pejorativamente pela imprensa de "fazedores de chuvas". Existia, contudo, aqueles que apostavam na instalação dos observatórios meteorológicos para "prever" as crises climáticas. Os primeiros justificavam que replantando as árvores, o que seria facilitado pela existência dos reservatórios, o clima melhoraria, tornando-se úmido. Isso aumentaria a probabilidade de chuvas regulares. Já os últimos afirmavam que as secas eram ocasionadas pelas manchas solares, que periodicamente atingiam as províncias nortistas. ${ }^{10}$ Assim, o ideal era "prever" o momento que essas manchas

8 NEVES, Frederico Castro. A seca e a cidade: a formação da pobreza urbana em Fortaleza (1880-1900). In: SOUZA, Simone; NEVES, Frederico Castro (org.). Seca. Fortaleza: Edições Demócrito Rocha, 2002. p. 75.

9 NEVES, Frederico de Castro. A multidão e a história: saques e outras ações de massas no Ceará. Rio de Janeiro: Relume Dumará; Fortaleza: Secretaria de Cultura e Desporto, 2000. p. 27.

10 As capitais que se encontram na atual região Nordeste do Brasil no século XIX eram denominadas províncias 
surgiriam, através da observação meteorológica, para comunicar aos habitantes do campo que se precavessem, guardando alimentos para sobreviver ao período de escassez ou migrando para áreas que não fossem atingidas pela falta de água. ${ }^{11}$

Após inúmeras discussões - realizadas, sobretudo, pelos intelectuais do Instituto Politécnico Brasileiro-RJ12 - em torno da melhor alternativa para se "combater" as estiagens, quando foram feitos largos elogios às ações implementadas pelos ingleses na Índia, os conselheiros relataram a importância de construir açudes, estradas de ferro e obras complementares que auxiliassem a eliminar esse mal-estar. ${ }^{13}$ Com esses propósitos, o governo imperial enviou uma comissão de engenheiros, em 1878, ao Ceará. A expectativa com a vinda dessa comissão era minorar a situação deplorável na qual se encontravam os habitantes da província. Para concretizar esse objetivo, analisaram a possibilidade de construir vias férreas, um novo porto em Fortaleza e projetos de açudes, sendo as regiões de Maranguape, Acaraú, Quixeramobim e Quixadá consideradas as mais propícias à açudagem. É interessante salientar, porém, que houve estudos semelhantes, realizados pela respectiva comissão, no sertão da Paraíba e do Rio Grande do Norte que "estudariam, projetariam e gerenciariam a construção de açudes, barragens e canais de irrigação juntamente com as estradas de ferro, as estradas carroçáveis e as de rodagem". ${ }^{14}$

A respectiva comissão, porém, foi dissolvida e outra, dedicada exclusivamente à construção de açudes no Ceará, foi organizada. Em 1879 adentraram no território cearense a Comissão de Açudes e sua comitiva de engenheiros, com o objetivo de estudar os locais mais indicados para a execução dos reservatórios. Dentre as localidades estudadas, o sertão de Quixadá foi escolhido. Averiguamos que essa escolha, para além dos fatores topográficos e técnicos, levou em consideração a proximidade daquela paragem com a cidade de Fortaleza, o que facilitaria o transporte dos materiais, o menor valor orçamentário e, sobretudo, a influência dos políticos de Quixadá, que indicaram aquele espaço físico como o local mais propício para a construção de uma barragem.

Quais expectativas envolveram a construção desse açude no sertão quixadaense? Como os sujeitos envolvidos nessa obra pública percebiam as benesses desse empreendimento

do Norte, havendo a divisão do país em cinco regiões (Norte, Nordeste, Sul, Sudeste e Centro-Oeste) somente no século XX.

11 DAVIS, Mike. Holocaustos coloniais: clima, fome e imperialismo na formação do terceiro mundo. Tradução de Alda Porto. Rio de Janeiro: Record, 2002.

12 O Instituto Politécnico Brasileiro foi criado em 1862, no Rio de Janeiro, com o intuito de estudar e difundir os conhecimentos teóricos e práticos dos diferentes ramos da engenharia e das ciências acessórias. MARINHO, Pedro Eduardo Mesquita de Monteiro. A engenharia imperial: o Instituto Politécnico Brasileiro e a organização da engenharia no Brasil do Segundo Reinado. ANPUH - XXII SIMPÓSIO NACIONAL DE HISTÓRIA - João Pessoa, 2003.

13 Para entender melhor essa discussão realizada pelos intelectuais do Instituto Politécnico Brasileiro sobre as possibilidades de "combater as secas" no Ceará, ver: ALVES, op. cit.; e CÂNDIDO, Tyrone Apollo Pontes. Trem da seca: sertanejos, retirantes e operários (1877-1880). Fortaleza: Museu do Ceará/Secretaria da Cultura do Estado do Ceará, 2005.

14 SILVA, Adriano Wagner da. Engenharia nos sertões nordestinos: o Gargalheiras, a barragem Marechal Dutra e a comunidade de Acari, 1909-1958. 2012. Dissertação (Mestrado em História) - Universidade Federal do Rio Grande do Norte, Natal, 2012. p. 22. 
hidráulico? Quais problemas ocorreram em Quixadá que inviabilizaram uma rápida execução desse reservatório? Essas são algumas questões que nos propusemos a discutir no respectivo artigo, ao analisarmos as nuanças e os percalços que envolveram a edificação do açude Cedro, entre 1884 e 1906.

A construção do açude Cedro, iniciada em fins de 1884, ficou sob a chefia do engenheiro inglês Jules Jean Revy, causando indignação e revolta em alguns profissionais brasileiros com a escolha de um estrangeiro para o cargo. A expectativa do engenheiro Revy era que a obra do açude de Quixadá melhorasse significativamente a agricultura e a vida dos camponeses cearenses, sendo qualificada por este como algo inédito na América. Esse caráter de ineditismo justificava-se por ser a primeira grande construção hidráulica direcionada para resolver problemas inerentes à seca. Outro grande defensor dessa obra de açudagem era o senador Henrique d'Ávila, que em diversas ocasiões empenhou-se em sua justificação. Quando exerceu o cargo de ministro da Agricultura (1882-83), por exemplo, insistiu para que o açude fosse construído, aprovando seu projeto. Na concepção do respectivo senador, muitas seriam as benesses advindas da construção desse açude, porque "esses reservatórios e a irrigação por eles [sic] feita farão a felicidade geral do povo". ${ }^{15}$

Além do senador Ávila, outro líder governista, o presidente da Província do Ceará Carlos Ottoni pronunciou-se em defesa da construção do reservatório:

\begin{abstract}
Vivamente interessado pela realisação deste maravilhoso emprehendimento, que sem dúvida mudará a face desta província, victima das mais desoladoras seccas, realisei uma viagem à bacia do Reservatório do Quixadá, em companhia do chefe da commissão Dr. J.J. Revy, afim de visitar os trabalhos preliminares de exploração e os valles irrigados do Satiá. Esta visita deixoume a mais grata das impressões, e della dei conhecimento ao Sr. ministro da Agricultura no telegramma que segue. - 'Estação dos telegraphos, 11 de janeiro de 1885. - Exm. ${ }^{\circ}$ Sr. Ministro d'Agricultura - Côrte. - Cheguei hontem do Quixadá, onde visitei com o Dr. Revy a grande bacia onde vai ser construído o reservatório, a cadeia circular de montanhas, as obras de exploração feitas pessoalmente pelo chefe da commissão para construcção das barragens, a zona que tem de ser desapropriada para o reservatório e a irrigação, e os trabalhos preliminares actualmente executados pela commissão. Tive a melhor impressão desta visita, e tendo-a terminado dirijo a V. Ex. os agradecimentos e congratulação desta província pela iniciação de tão auspicioso melhoramento, que é questão de vida para o Ceará. ${ }^{16}$
\end{abstract}

O objetivo do presidente da província era demonstrar para os habitantes do Ceará e para outros grupos da sociedade brasileira que o governo imperial estava envolvido na construção dessa grande obra pública, assim como acreditava na sua eficácia para solucionar o problema das estiagens. Acreditava-se que ao se construir esse "maravilhoso" reservatório e os canais de irrigação, a paisagem sertaneja seria transformada profundamente. As cidades que sofriam periodicamente com as "mais desoladoras seccas" também seriam beneficiadas, assim como

15 Jornal Libertador, Ceará, 4 set. 1884. Biblioteca Pública Menezes Pimentel/CE.

16 Relatório com que o Exm. ${ }^{\circ}$ Sr. Comendador Dr. Carlos Honório Benedicto Ottoni passou a administração da Província do Ceará, 1885, p. 105. Acervo particular. 
se desenvolveria a agricultura no Ceará, tornando-a moderna, produtiva e rentável. Dessa forma, supõe-se que, para essas pessoas, a concretização desse projeto de açudagem fosse de suma importância, pois, além de fortalecer a influência dos políticos situacionistas, seria um símbolo do poder imperial na região sertaneja. Afora isso, sob o viés técnico e científico, representaria a vitória da humanidade sobre as intempéries da natureza.

Percebemos que formular discursos que persuadissem a opinião dos grupos oposicionistas era essencial para os representantes do governo imperial. Afinal, como salienta o presidente da Província do Ceará Carlos Ottoni, o Cedro era "questão de vida para o Ceará". Além disso, suas palavras expressam a urgência em construir um grande açude que solucionasse definitivamente os problemas relacionados à seca no Ceará. E com esta expectativa foi enviada para o sertão de Quixadá, em 1884, uma equipe de engenheiros e auxiliares, que ali se juntou a pedreiros, ferreiros, mecânicos, feitores, vaqueiros e outros trabalhadores - vindos da Europa, de várias partes do Brasil e de outras localidades do Ceará. Alguns com experiência na construção de obras públicas, outros sem nenhuma experiência anterior.

Mas, de acordo com o historiador Tyrone Cândido, o engenheiro inglês Jules Jean Revy era criterioso na escolha dos sujeitos com quem trabalhava. Durante a seca que atingiu a província do Ceará em 1889, por exemplo, deixou de "engajar até 3 mil retirantes na construção do açude de Quixadá", preferindo um número menor (300 trabalhadores), "composto por 'homens escolhidos', pois desse modo julgava obter um resultado superior nos trabalhos". Inclusive, antes de iniciar as obras no açude viajou para a região da Lombardia (Itália), no intuito de conhecer as obras de irrigação empreendidas naquele lugar, assim como contratar trabalhadores especializados. Posteriormente mandou vir ainda maquinistas ingleses de Londres. $^{17}$

Através de outro documento, um telegrama enviado ao engenheiro Revy, é possível perceber mais nitidamente a movimentação desses trabalhadores qualificados por grandes obras no Brasil:

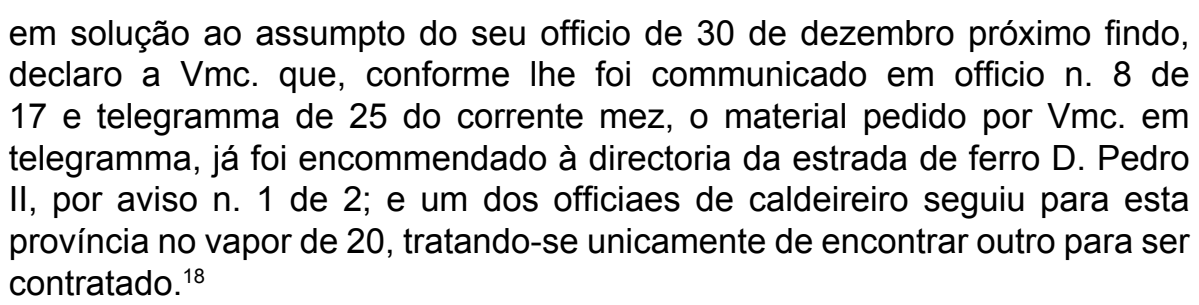

A companhia de estradas de ferro D. Pedro II, criada em meados do século XIX para interligar as regiões do Rio de Janeiro, São Paulo e Minas Gerais, se organizou a partir da pressão dos cafeicultores no Brasil, que objetivavam facilitar o escoamento do café pelo país. ${ }^{19}$ No

17 CÂNDIDO, op. cit., 2019, p. 282.

18 Ofício enviado ao engenheiro Jules Jean Revy, em 28 de janeiro de 1885. Ministério da Agricultura, A-U, p. 41. Disponível em: http://www.crl.edu/brazil/ministerial/agricultura.

19 MARINHO, Pedro Eduardo Mesquita de Monteiro. Companhia Estrada de Ferro D. Pedro II: a grande escola 
período citado no telegrama (janeiro de 1885), as obras de prolongamento da ferrovia, assim como reparação e conclusão de estações, encontravam-se na região de Minas Gerais. Dessa forma, percebe-se que havia uma interlocução entre os engenheiros responsáveis por essas construções - estrada de ferro D. Pedro II e açude Cedro -, havendo inclusive a permuta de trabalhadores especializados. Mas por que o caldeireiro seguiu para a província do Ceará, ao invés de permanecer na região mineira? Seria mais fácil para o engenheiro responsável pela ferrovia repor essa mão de obra especializada, sobretudo, devido à proximidade com a corte imperial? A preferência do engenheiro Revy por uma mão de obra especializada influenciou na circularidade desse trabalhador?

Se por um lado havia aqueles que defendiam ardorosamente o açude Cedro depositando nele grande expectativa, por outro, havia aqueles que se posicionavam contra a sua construção, bradando palavras que o desacreditavam perante a sociedade brasileira. Um dos principais opositores era o engenheiro civil Aarão Reis, que afirmava que a obra não representaria nenhuma novidade para o país, pois já haviam sido construídas diversas represas e reservatórios em diversas regiões. O respectivo engenheiro condenava ainda a nomeação de um estrangeiro para o cargo de chefe da Comissão de Açudes, o já citado inglês Jules J. Revy, quando havia inúmeros bons profissionais formados nas escolas de engenharia no Brasil. Os opositores afirmavam também que o reservatório poderia até beneficiar algumas áreas do sertão de Quixadá, mas em hipótese alguma toda a província cearense. Além disso, os mesmos apontavam diversas falhas técnicas do projeto de açudagem, envolvendo-se em árduos debates contra aqueles que o defendiam.

Outros que também não percebiam a construção do açude Cedro com grande entusiasmo eram os camponeses. Percebemos que esses trabalhadores recorriam à referida construção quando havia poucas oportunidades de trabalho ou quando ainda era inviável retornar à agricultura, sobretudo, nos períodos de estiagem. Portanto, muitos visualizavam o emprego nas obras do açude como algo passageiro. A incompatibilidade entre as atividades realizadas cotidianamente no campo e as praticadas no reservatório de Quixadá explicam esse posicionamento. Quantas dessas pessoas haviam trabalhado em pedreiras, extraindo e carregando pedras? Já haviam trabalhado sob a fiscalização de feitores e seguindo criteriosamente o ritmo do relógio? Mesmo que alguns tivessem alguma experiência, adquirida na própria Comissão de Açudes em épocas anteriores, isso não os motivava a permanecer em Quixadá. Pelo contrário, imagina-se que esse fosse um dos motivos que os desencorajava a continuar ali. O próprio engenheiro responsável pela obra em 1890, Ulrico Mursa, admitia que fosse necessário "elevar ainda mais o salário, talvez a 1.500 réis, pelo menos para o pessoal empregado no concreto, serviço pesado do qual todos fogem". ${ }^{20}$ Vê-se, portanto, que

prática da nascente engenharia civil no Brasil oitocentista. Topoi, Rio de Janeiro, v. 16, n. 30, p. 203-233, jan.jun. 2015.

20 Relatório do trimestre de janeiro a março de 1893, p. 107. Balancete da Comissão de Açudes e Irrigação. Acervo DNOCS/CE. 
continuar na construção exercendo serviços tão incompatíveis com as práticas realizadas no campo constituía algo que desestimulava esses sertanejos.

A documentação que retrata o cotidiano do trabalhador é escassa, mas, a partir de algumas fontes é possível entender a organização desse trabalho realizado no açude Cedro:

Depois de conversar com o Dr. Loureiro e para que o serviço de melhoramento da estrada não encontrasse entraves, resolvi que elle montasse o serviço entre Canoa e Joazeiro do modo que se segue e que pode servir de norma ao que V. S. montar de Quixadá para Joazeiro; assim ficou elle constituído: - empregando 50 trabalhadores, 2 burros para conducção da água, 2 outros para conducção de mantimentos, 10 animaes para o serviço dos empregados da comissão; - fornecendo gratuitamente a cada trabalhador, diariamente, 1 litro de farinha, 1 litro de feijão, 1 litro de arroz; - começando o trabalho às 6 horas e terminando às 11 horas, para começar de novo às 2 horas e terminar às 6 da tarde, convindo, principalmente pela manhã, que esse serviço seja seguido a risca; devendo os trabalhadores serem escolhidos entre os melhores (sendo possível dos próprios moradores e ahi dos de Quixadá); - fazendo o pagamento do pessoal operário, inclusive apontadores, todos os domingos, para que o remetterei ao Gusmão o dinheiro necessário da Fortaleza, indo esse pessoal receber em Canoa, o do Dr. Loureiro, e em Quixadá o que V. S. montar. ${ }^{21}$

Assim, tendo como parâmetro a construção da estrada de rodagem realizada entre 1884 e 1885, compreendemos mais detalhadamente o cotidiano na obra do açude: para a concretização do trajeto entre as localidades de Canoa e Juazeiro, alistaram-se 50 trabalhadores que começavam "o trabalho às 6 horas e terminando às 11 horas, para começar de novo às 2 horas e terminar às 6 da tarde". O que teria, contudo, motivado esses sujeitos a se alistarem na obra do açude: a irregularidade das chuvas, o dinheiro pago pela Comissão de Açudes ou as péssimas condições de trabalho no campo, no qual (possivelmente) exerciam atividades nas terras de grandes proprietários? ${ }^{22}$

Uma das táticas empregadas pelos engenheiros para evitar a debandada maciça de trabalhadores foi aumentar a diária de pagamento, pelo menos daqueles que se enquadrassem no perfil desejado, ou seja, capazes de aguentar o trabalho árduo. Afinal, se não era possível conseguir outros, que permanecessem pelo menos o pessoal já empregado. Mas, ao analisarmos os sete livros de Ponto Geral dos Serviços do Açude de Quixadá (1891-1906), ${ }^{23}$ notamos que essa manobra não obteve os resultados esperados, já que a movimentação dos sertanejos (entrando e saindo) continuou intensa e constante, principalmente a partir de 1892, quando as chuvas voltaram a cair regularmente no sertão quixadaense. Em janeiro de

21 Ofício do engenheiro hidráulico Jules Jean Revy para o $1^{\circ}$ engenheiro Costa Couto em 12 de dezembro de 1884. Ministério da Agricultura, 1885, A-U, p. 50. Disponível em: http://www.crl.edu/brazil/ministerial/ agricultura.

22 Havia diversas formas de prestação de serviços realizados pelos trabalhadores sertanejos no campo, como a função de vaqueiros, diaristas e parceiros, sendo em todos os casos bastante comum a relação de dependência com os grandes proprietários rurais.

23 Essa documentação não possui organização arquivista adequada e está mal acondicionada em um galpão do DNOCS, no Campus do Pici e no Museu das Secas, na rua Pedro Pereira, bairro Centro, ambos em Fortaleza$\mathrm{CE}$, havendo o risco de ser totalmente danificada pela ação do tempo, da natureza e por causa da ação de insetos e outros animais. Alguns livros, contudo, foram transferidos para a sede do DNOCS, na avenida Duque de Caxias, bairro Centro/Fortaleza-CE. 
1892, por exemplo, o aumento do pagamento de 900 para 1.000 réis não foi suficiente para manter na construção os trabalhadores João Bento de Sousa - trabalhou no dia 5, retornando somente no dia 11 -, Feliciano Félix da Silva - veio nos dias 5, 11 e 12 -, João Pessoa da Rocha e Manoel Pessoa da Rocha, que vieram nos dias 2 e $4 .{ }^{24}$

O caso mais interessante foi, contudo, o de Silvino Pimenta. Além de possuir outros familiares na obra - o aprendiz de ferreiro Laurentino Pimenta e o trabalhador Elias Pimenta - e sair da função de aprendiz de ferreiro para o cargo de trabalhador (onde recebia mais), seu nome aparece riscado várias vezes nos livros de ponto: a primeira vez foi em junho de 1893, por não ter comparecido em nenhum dia ao trabalho. Retornou, porém, em setembro do mesmo ano. Trabalhou até junho de 1894 na turma 09, quando foi novamente desligado da comissão por não ter comparecido nenhum dia. Seu retorno ocorreu em julho do mesmo ano, mas agora na turma $07 .{ }^{25}$ Por que saiu e voltou tantas vezes? É possível que o motivo de seu retorno fosse o aumento das diárias. A primeira vez que voltou passou a ganhar 1.200 réis, um pouco acima do que o recebido por outros trabalhadores. Na segunda vez, retornou quando houve um aumento geral nos pagamentos, promovido pelos dirigentes da Comissão de Açudes.

Imaginamos que essa grande evasão nas obras constituía uma estratégia de resistência aos trabalhos no açude. Na perspectiva de James Scott, aos camponeses restavam ínfimas alternativas, pois, "pulverizados ao longo da zona rural", enfrentavam "ainda mais obstáculos para a ação coletiva e organizada". Desse modo, "as formas cotidianas de resistência parecem particularmente importantes". A saída definitiva, as faltas alternadas, a volta aos trabalhos, dentre outras artimanhas, quiçá constituíssem uma "resistência popular" por meio da qual os trabalhadores alcançavam seus objetivos pacificamente, sem qualquer enfrentamento direto com as autoridades governamentais. ${ }^{26}$

É importante ressaltar, porém, que as críticas à construção do açude Cedro diminuíam nos períodos de estiagem (1889, 1898 e 1900), já que se acreditava que através das atividades realizadas ali se conseguiria amenizar o caos instaurado pela crise climática: dezenas de retirantes adentrando diariamente a cidade de Quixadá, vagando com seus corpos macérrimos e fétidos em busca de comida. A simples presença dessas pessoas atemorizava a sociedade abastada da região e exigia medidas urgentes para que fossem evitadas as mesmas cenas de desespero registradas durante a seca de 1877-79. Assim, muitas eram as vozes favoráveis a essa construção, pois depositavam grandes expectativas em relação ao impacto da mesma, como é perceptível nas palavras do imperador D. Pedro II, intermediadas pelo engenheiro Jules Revy.

24 Livro de Ponto Geral dos Serviços do Açude de Quixadá, 1892, p. 100.

25 Livros de Ponto Geral dos Serviços do Açude de Quixadá: setembro de 1893, p. 63, junho de 1894, p. 197 e julho de 1894, p. 10.

26 SCOTT, James C. Formas cotidianas da resistência camponesa. Raízes: revista de ciências sociais e econômicas, Campina Grande, v. 21, n. 1, p. 10-31, 2002, p. 11-12. 
Antes de minha sahida do Rio de Janeiro, o senhor Dom Pedro $2^{\circ}$ concedeume uma audiência em Petrópolis, na qual o Chefe do Estado muito se interessou pela sorte do povo do Ceará, e pelos meios de athenuar os effeitos desastrosos de seccas periódicas pela construção de grandes depósitos d'água, e a introdução do systema moderno de irrigação de terras de agricultores em grande escala. Lembrou também a conveniência de localisar o povo, caso 1889 fosse anno de secca, dando o Governo trabalho e supprimento de meios à população; evitando quando possível a emigração fora da Província; e desejando ardentemente que o povo não deixasse os seus lares durante seccas vindouras. ${ }^{27}$

A principal preocupação do imperador, assim como dos políticos e da elite cearense, estava relacionada à movimentação dos sertanejos em direção às principais cidades do Ceará ou para outras regiões do país. Como salienta o historiador Tyrone Cândido, durante a seca de 1888-89, na tentativa de conter os sertanejos, o governo imperial investiu em três grandes obras: "os prolongamentos das ferrovias de Baturité e de Sobral e a construção do grande açude de Quixadá". ${ }^{28}$ Esperava-se que, ao dar prosseguimento ao trabalho realizado no sertão de Quixadá, assim como alimentos para os inválidos, conseguiriam persuadir os retirantes a manterem-se em seus lares ou nas localidades próximas à obra, evitando, por conseguinte, outras possíveis dificuldades provenientes da crise climática, tal como a invasão da capital, Fortaleza.

A invasão dos retirantes ao espaço urbano durante as grandes secas do século XIX e início do século XX, contudo, não foi exclusividade da capital cearense, já que outras regiões também sofreram com esse problema. Em Natal (Rio Grande do Norte), devido à seca que assolou a região entre 1902 e 1904, uma multidão (aproximadamente 15 mil pessoas) recorreu às obras governamentais, tais como melhoramento do porto, abertura e alargamento das ruas, para sobreviver às intempéries climáticas. ${ }^{29} \mathrm{Na}$ capital baiana, Salvador, a chegada dos retirantes, entre as secas de 1877-79 e 1889-1890, amedrontou a elite, passando a imprensa local a exigir dos governantes a distribuição de alimentos e, sobretudo, a criação de trabalhos no campo, evitando-se assim a migração desses sujeitos para outras regiões da Bahia. ${ }^{30}$

A expectativa era a de que, por meio da construção dos reservatórios e de modernos canais de irrigação, fossem atenuados os "effeitos desastrosos de seccas periódicas". Esses equipamentos, além disso, proporcionariam para os camponeses uma agricultura mais rentável e uma maior independência com relação às estações climáticas. Aliás, como visto em outros momentos, esse discurso era largamente utilizado pelos representantes do poder imperial para legitimar o açude Cedro. Desejando "ardentemente que o povo não deixasse os

27 Relatório enviado pelo engenheiro Revy ao governador do Estado do Ceará, em 31 de dezembro de 1889. Fundo: Açudes e Irrigações - BR APEC, Al. Data Tópica: Quixadá. Caixa 2. Arquivo Público do Estado do Ceará.

28 CÂNDIDO, op. cit., 2019, p. 183.

29 FERREIRA, Ângela L. A. Os "indesejáveis" na cidade: as representações do retirante da seca (Natal, 18901930). Scripta Nova - Revista Eletrônica de Geografia y Ciencias Sociales, Universidade de Barcelona, n. 94, agosto de 2001.

30 GONÇALVES, Graciela Rodrigues. As secas na Bahia do século XIX (sociedade e política). 2000. Dissertação (Mestrado em História) - Universidade Federal da Bahia, Salvador, 2000. 
seus lares durante seccas vindouras", o imperador D. Pedro II finalizou sua conferência com o engenheiro Revy e autorizou-o a reiniciar os trabalhos no sertão de Quixadá, que haviam sido interrompidos em 1885 devido às denúncias de irregularidades durante os trabalhos preparatórios.

Durante a seca de 1889 deslocaram-se para a cidade de Quixadá milhares de pessoas, na expectativa de obter alimentos e alguma ocupação. Mas a existência dessa multidão atemorizava as autoridades, já que esses sujeitos poderiam se revoltar contra as precárias condições de vida nas obras daquele reservatório, tal como ocorreu no dia 19 de março de 1889 - data emblemática, pois se comemora o dia de São José, padroeiro do Ceará. O engenheiro Revy relatou que

de carta recebida hoje de Quixadá do Snr. Secretário desta Commissão, do Rvno Sne vigário da freguesia e de outros, sou informado de scenas desagradáveis na última distribuição de víveres do dia 19 do corrente, sendo evitados ferimentos pelo destacamento que em tempo tomou posse do depósito da Commissão.

Cerca de duas mil pessoas do povo cercaram o depósito da Commissão no mesmo dia 19, insistindo pela distribuição de víveres a todos, quando o Snr. Secretário, em vista de um incidente ocorrido no dia 17 , só queria distribuir aos velhos e aos aleijados, tendo antes, conforme as minhas instrucções, distribuindo gêneros a todas as mulheres, distribuição esta que correu sem a menor difficuldade.

Diz o Snr. Secretário: "Depois da distribuição de sabbado último (17) a maior parte dos homens venderam na feira as suas rações por preço miserável, constando mais terem se reunido os negociantes d'ali para, de commum accordo, comprarem todo o gênero, promettendo melhorar o preço".

Parece, portanto, que a desordem do dia 17 foi a consequência do plano dos negociantes de apoderarem-se dos gêneros da Commissão a preços insignificantes, servindo o povo de instrumento inconsciente para essa usurpação dos gêneros dos depósitos. ${ }^{31}$

Este episódio causou tanto terror entre aqueles que residiam em Quixadá que muitas foram as cartas enviadas ao chefe da Comissão de Açudes (que estava longe, possivelmente em Baturité ou até em Fortaleza). Comunicavam os fatos ocorridos ali e exigiam soluções imediatas para que fossem evitadas as terríveis cenas registradas no dia 19 de março naquela paragem. Mas esse enredo foi escrito anteriormente, no dia 17 do mesmo mês, quando o secretário da comissão, Francisco Pinto, proibiu a distribuição de alimentos para todas as pessoas. Este orientava que somente velhos e aleijados deveriam receber tal benefício. Mas, como salientou Revy, sob a orientação deste, decidiu-se distribuir também para as mulheres. É interessante perceber que Revy posicionou-se como um negociador entre os retirantes e Francisco Pinto. É certo, de todo modo, que o importante era evitar uma explosão geral de revolta. A negociação, afinal, era primordial nesse momento de tensão, como salienta Neves:

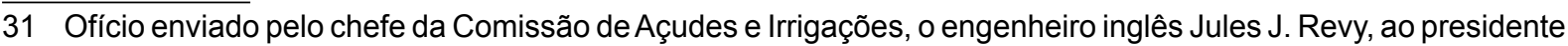
da Província do Ceará Caio da Silva Prado, em 21 de março de 1889. Fundo: Açudes e Irrigações - BR APEC, Al. Data Tópica: Quixadá, APEC. Arquivo Público do Estado do Ceará. 
[...] a aglomeração de pessoas à espera de solução é o principal argumento e, ao mesmo tempo, o mais poderoso meio de pressão que os retirantes trazem para o cenário da 'negociação'; e a fome - ou a perspectiva de passar fome - é a motivação essencial. O crescente volume da multidão constitui uma pressão irresistível, que precisa ser neutralizada antes que a revolta tome conta dos espíritos, outrora pacíficos e conformados, dos homens do campo. $^{32}$

Percebe-se, contudo, que houve momentos que a experiência em persuadir os retirantes através da negociação não deu certo. Tal como ocorreu no dia 20 de dezembro de 1889, quando um grupo de trabalhadores, revoltados com a ordem que extinguia a distribuição de alimentos na região de Quixadá, tentou saquear o armazém de gêneros do governo, ocorrendo um confronto direto com a "força pública". No conflito morreram os trabalhadores Antônio Francisco de Souza e Antônio Mello Paula, ficando feridos os soldados José Moreira de Souza, Ferreira Lima e Victaliano de Lima. O delegado, após o ocorrido, determinou que os soldados continuassem na localidade para "manutenção da ordem pública", instaurando um inquérito para apurar quem eram os culpados pelo conflito. ${ }^{33}$

Além desses confrontos, havia ainda a preocupação, entre engenheiros e proprietários de terras, de que esses trabalhadores migrassem para outros locais do Brasil. Ambos viam a mão de obra barata se esvair de seu domínio.

Por toda parte o clamor se faz ouvir, não só nos serviços do governo como até mesmo na própria pequena lavoura de particulares do estado. É um grande mal que ameaça tanto a este como a todo e qualquer emprehendimento material no Ceará, mas para o qual não vejo remédio efficaz, porque esta vida de nômade do cearense é um dos seus característicos, de sorte que por mais fortes que sejam os obstáculos que o governo estadual lhes crie para evitar ou deter a corrente de emigração que annualmente cresce para o Amazonas, não poderá jamais detê-la, irá naturalmente, em seu censo, aumentando assim as nossas dificuldades. ${ }^{34}$

O "clamor" era proferido por inúmeros indivíduos: por representantes do estado do Ceará, por aqueles que dirigiam obras públicas e por "particulares". O que todos temiam era perder a mão de obra sertaneja, abundante e barata. O que poderiam fazer para evitar isso? O engenheiro recomendava que o governo tomasse as rédeas da situação e desenvolvesse métodos para dificultar a debandada desses sertanejos, pois grande parte deles dirigia-se para a região Norte do Brasil, iludida por um enriquecimento fácil e motivada ainda por familiares e amigos, que migraram antes e descreviam para eles histórias fabulosas. ${ }^{35}$ Vale ressaltar, contudo,

32 NEVES, op. cit., 2000, p. 10.

33 Ofício da Secretaria de Polícia, 24 de dezembro de 1889. Livro 216. Fundo: Governo do Ceará. Fundo: Chefatura de Polícia/APEC. Arquivo Público do Estado do Ceará.

34 Relatório do trimestre de abril a junho de 1894, p. 141-142. Balancete da Comissão de Açudes e Irrigações. Acervo DNOCS/CE.

35 Para entender melhor esse fluxo migratório para a região Norte, a partir de meados do século XIX e, sobretudo, partir da seca de 1877-79, ver: CARDOSO, Antônio Alexandre Isidio. Nem sina, nem acaso: a tessitura das migrações entre a Província do Ceará e o território amazônico (1847-1877). 2011. Dissertação (Mestrado em História Social) - Universidade Federal do Ceará, Fortaleza, 2011; LACERDA, Franciane Gama. Migrantes cearenses no Pará: faces da sobrevivência (1889-1906). 2006. Tese (Doutorado em História Social) - Faculdade de Filosofia, Letras e Ciências Humanas, Universidade de São Paulo, São Paulo, 2006; 
que durante as secas que atingiram o Ceará em fins do século XIX, além da migração para a região nortista, houve uma intensa movimentação de trabalhadores cearenses para os cafezais de São Paulo. ${ }^{36}$

Quando as primeiras chuvas caíam no Ceará, esses trabalhadores - considerados por alguns engenheiros e membros da elite letrada como uma massa inconsciente - decidiam retornar para seus lares e para as atividades na agricultura. Por mais que as condições de trabalho no campo, possivelmente nas propriedades de outros, pudessem ser exploratórias, esses homens percebiam as obras no açude de Quixadá como algo provisório. Esse trabalho tinha importância na medida em que os auxiliava na obtenção de comida, que Ihes saciaria a fome durante as secas; quando havia estabilidade climática, muitos retornavam às suas casas, pois não incorporaram a construção desse reservatório como um novo lugar permanente de trabalho. E mesmo quando houve a tentativa de tornar alguns desses camponeses uma mão de obra especializada, com a organização de turmas de aprendizes, percebe-se que a rejeição continuou existindo.

O que se percebe, ao analisar a documentação, é que as expectativas em torno dessa obra pública arrefeceram com o passar do tempo. Durante o Império, apesar das críticas e dos oponentes ao projeto de açudagem, esta era percebida como um maravilhoso empreendimento que mudaria o aspecto entristecedor da província cearense durante as secas, sendo um dos símbolos do poder imperial no sertão do Ceará. Mas, durante os primeiros anos do governo republicano (decretado em fins de 1889), começou a ser questionada por muitos intelectuais e políticos que compunham a cúpula situacionista. Comumente, os engenheiros da Comissão de Açudes e Irrigações pronunciavam palavras enaltecedoras para legitimá-la, como fica explícito no discurso de Ulrico Mursa:

[....] em bem desta obra sagrada para o Ceará, em bem deste emprehendimento, que uma vez concluído, marcará o início de uma nova vida próspera e feliz para a população deste território tão cruelmente tratado pela natureza. ${ }^{37}$

O discurso de Mursa, apesar de assemelhar-se a tantos outros pronunciados por aqueles que defendiam o açude Cedro, vinha endossar esse coro e alertar as autoridades governamentais sobre a importância de tê-lo concluído; pois somente dessa forma poder-se-ia fazer prosperar o estado e trazer alegria para a população cearense. Afinal, era uma obra "sagrada" para

NETO, Edgar Braga. Emigração Cearense entre 1888 e 1915: sentidos, controle e configuração social dos migrantes. 2012. Dissertação (Mestrado em Sociologia) - Universidade Federal do Ceará, Fortaleza, 2012; e BARBOZA, Edson Holanda Lima. A hidra cearense: rotas de retirantes e escravizados entre o Ceará e as fronteiras do Norte (1877-1884). 2013. Tese (Doutorado em História Social) - Pontifícia Universidade Católica de São Paulo, São Paulo, 2013.

36 Para entender melhor essa migração para a região dos cafezais paulistas, durante as grandes secas que atingiram o Ceará no final do século XIX, em uma tentativa de suprir e/ou substituir a mão de obra escrava, ver: GONÇALVES, Paulo César. Migração e mão de obra: retirantes cearenses na economia cafeeira do Centro Sul (1877-1901). São Paulo: Associação Editorial Humanitas, 2006; e MOURA, Denise Aparecida Soares de. Andantes de novos rumos: a vinda de migrantes cearenses para fazendas de café paulistas em 1878. Revista Brasileira de História, São Paulo, v. 17, n. 34, p. 1-5, 1997.

37 Relatório do trimestre de julho a setembro de 1894, p. 149. Balancete da Comissão de Açudes e Irrigações. Acervo DNOCS/CE. 
aquelas pessoas e para aquela região e, como tal, não poderia ser questionada. É perceptível a tentativa de tornar o reservatório de Quixadá um marco histórico para o Ceará e seus habitantes: sob um viés técnico-científico, promoveria o desenvolvimento do sertão e domaria as intempéries da natureza, tornando os sertanejos mais independentes das oscilações climáticas. Outros defensores recomendavam ainda que a experiência positiva com a construção dessa grande obra fosse espalhada por todo o país, servindo como modelo.

Vale ressaltar que esse discurso enaltecedor dos políticos situacionistas e de outros que outrora defendiam o reservatório de Quixadá não se sustentou até a inauguração oficial do mesmo, em 1906. ${ }^{38}$ Ao menos, não se percebe muita empolgação nas palavras pronunciadas pelo presidente do Brasil Afonso Pena, durante sua visita ao sertão de Quixadá: "Está muito bonito, mas isto apenas atesta o desperdício dos dinheiros públicos". ${ }^{39}$ Por que o criticava? Por ser simbolicamente um empreendimento que representava o poder do Império? Ou o impasse estaria relacionado simplesmente aos gastos, considerados, desde 1885 , exorbitantes? É complicado descobrir quais as intenções de Pena, tendo em vista que não existam fontes que descrevam outras opiniões sobre esse acontecimento.

A decepção com o projeto de irrigação e com a eficácia do açude Cedro em solucionar definitivamente o problema da seca no Ceará, possivelmente contribuiu para essa mudança na expectativa em torno dessa obra pública, entre o final do século XIX e início do século XX; e para a construção de uma imagem de inutilidade, tal como Euclides defendeu no livro Os sertões. Mas será que o reservatório era mesmo único, monumental e inútil?

\section{Considerações finais}

"O REI DOS NOSSOS AÇUDES". Assim a revista O Malho (1935) intitulava a matéria referente ao açude Cedro (Quixadá-CE). A proposta era exaltar o reservatório, considerando a mais antiga obra hidráulica construída no Brasil como uma obra "pharaônica" e de "arte". Além disso, percebe-se que a respectiva revista procurava amenizar as possíveis críticas referentes à funcionalidade do açude:

Há outros reservatórios mais importantes, talvez, pela quantidade maior de terras que fertilizam, pelas aquisições da engenharia moderna que possuem; mas nenhum Ihe conquista a palma que detém, com justiça, pela belleza das legendas, pela enorme folha de benefícios que espalhou e pela somma de merecimentos que desfruta. ${ }^{40}$

38 É importante ressaltar que não houve uma inauguração oficial do açude Cedro, pois, apesar de o presidente Afonso Pena ter vindo ao Ceará em junho de 1906, não houve festa ou qualquer comemoração para festejar essa obra pública. Mas utiliza-se esta data como marco do término da obra. Nesse período foram finalizados os trabalhos de embelezamento do reservatório. Possivelmente não houve comemoração, porque desde 1898 o açude já estava quase completamente construído e já servia à população de Quixadá; e principalmente porque sua importância para as pessoas já havia caducado.

39 SOBRINHO, Thomaz Pompeu. História das secas (século XX). Mossoró: Coleção Mossoroense, volume CCXXVI, 1982. p. 199.

40 O Malho, Rio de Janeiro, 28 mar. 1935. Hemeroteca Digital da Biblioteca Nacional. 
Dessa forma, após quase três décadas de sua conclusão, ainda encontramos sujeitos debatendo sobre a importância do açude Cedro no "combate" às secas no Ceará, que deveria ser seguido como exemplo para a construção de outras obras hidráulicas. As críticas quanto à sua funcionalidade eram recorrentes nesse período? O que de fato modificou-se a partir da construção desse reservatório?

Consideramos que, apesar das expectativas quanto à utilidade do Cedro não terem sido completamente concretizadas, houve mudanças significativas na região sertaneja, a partir dessa construção. Criaram-se jornais, associações, círculos literários, um horto florestal e outros equipamentos que possibilitaram ares de progresso à cidade de Quixadá. Além disso, a partir da experiência com a construção do açude Cedro e da criação das diversas comissões de estudos, organizou-se em 1904 a Comissão de Estudos e Obras contra os Efeitos das Secas, que se tornaria a Inspetoria de Obras Contra as Secas (IOCS) em 1909, institucionalizando-se assim a luta contra as intempéries climáticas no Nordeste.

Recebido em: 25/06/2020

Aprovado em: 15/08/2020 